\title{
Prevalence and associated factors of cardio-metabolic risk factors in Iranian seafarers
}

\author{
Fereshteh Baygi ${ }^{1}$, Olaf C. Jensen ${ }^{2}$, Mostafa Qorbani ${ }^{3,4}$, Aliasghar Farshad ${ }^{1}$, Seyed Ali Salehi ${ }^{5}$, \\ Fatemeh Mohammadi-Nasrabadi ${ }^{6}$, Hamid Asayesh ${ }^{7}$, Farzad Shidfar ${ }^{1}$ \\ ${ }^{1}$ Occupational Health Research Centre, Iran University of Medical Sciences, Tehran, Iran \\ ${ }^{2}$ Centre of Maritime Health and Society, Institute of Public Health, University of Southern Denmark, Esbjerg, Denmark \\ ${ }^{3}$ Department of Public Health, Alborz University of Medical Sciences, Karaj, Iran \\ ${ }^{4}$ Non-communicable Diseases Research Centre, Endocrinology and Metabolism Population Sciences Institute, \\ Tehran University of Medical Sciences, Tehran, Iran \\ ${ }^{5}$ National Iranian Tanker Company, Tehran, Iran \\ ${ }^{6}$ Department of Food and Nutrition Policy and Planning Research, National Nutrition and Food Technology Research Institute, \\ Faculty of Nutrition Sciences and Food Technology, Shahid Beheshti University of Medical Sciences, Tehran, Iran \\ ${ }^{7}$ Department of Medical Emergencies, Qom University of Medical Sciences, Qom, Iran
}

\begin{abstract}
Background: Since Iran's economy is based on the sale of petroleum products, seafaring is considered a crucial job. Little research has been done on issues related to seafarers' health in Iranian maritime industry. The present study investigated the prevalence and associated factors of cardio-metabolic risk factors in seafarers of National Iranian Tanker Company (NITC).

Materials and methods: A cross-sectional study was performed on 234 Iranian male seafarers of NITC in 2015. Metabolic syndrome (MetS) was diagnosed according to the reports of National Committee of Obesity. Three main blood parameters (of elevated total cholesterol, elevated low-density lipoprotein cholesterol, and elevated very low-density lipoprotein cholesterol) and general obesity were included as additional cardio-metabolic risk factors.

Results: The mean age of the participants was $36.0 \pm 10.3$ years. The prevalence of MetS was $14.9 \%$. The common cardio-metabolic risk factors were excess weight (51.1\%), abdominal obesity (38.5\%), and smoking (27.8\%) among Iranian seafarers. In multivariate analysis, age (OR: 1.05, 95\% Cl: 1.01-1.09) and body mass index (OR: 1.14, 95\% Cl: 1.01-1.27) were associated with the increase in hypertension risk. Conclusions: Our finding showed that the current prevalence of MetS among Iranian male seafarers working on tankers can affect negatively their health and career at sea.
\end{abstract}

(Int Marit Health 2016; 67, 2: 59-65)

Key words: metabolic syndrome, seafarer, cardiovascular, prevalence

\section{INTRODUCTION}

Metabolic syndrome (MetS) presents a group of metabolic disorders including insulin resistance, central obesity, dyslipidaemia, glucose intolerance, and hypertension [1]. MetS is diagnosed according to the recommendations of National Committee of Obesity [2]. Several studies have showed that MetS is associated with increased risk of diabetes type 2, cardiovascular diseases, and the mortality rate of cardiovascular diseases by 6,5 and 2 times, respectively
$[1,3]$. Globally, the prevalence of MetS has increased in the past 20 years [1]. Based on published studies, the prevalence of MetS in developing countries ranges from 13\% in China to $30 \%$ in Iran [4]. Also, the prevalence of MetS was 25.9\% among male Danish seafarers [5]. Recent studies suggest that nutritional factors, shift work, sleep patterns [6], work stress [7], and fatigue [8] may play a critical role in the increase in MetS risk. Recently, few studies have assessed the prevalence of cardio-metabolic and associated 
risk factors among seafarers $[5,9,10]$. The study which was conducted among German seafarers showed that the prevalence of high blood pressure and high triglycerides were $49.7 \%$ and $41.6 \%$, respectively [9]. Other studies have also suggested that the majority of seafarers' death is related to cardiovascular diseases, which was from 27 to 45 per 100,000 [11].

Since Iran's economy is based on the sale of petroleum products, seafaring is considered a crucial job. Little research has been done on issues related to seafarers' health in Iranian maritime industry. Hence, the present study was set to assess the prevalence of cardio-metabolic and associated factors in Iranian male seafarers working in National Iranian Tanker Company (NITC).

\section{MATERIALS AND METHODS}

A cross-sectional study was performed on 234 Iranian male seafarers of NITC who referred to Health Unit of the company for their annual health examination from the beginning of April 2015 until the end of September 2015. All seafarers with complete demographic data and with at least 6 months of sea service were included in the study. The health examination data encompassed seafarers' age, height, weight, waist circumference, lipid profile, fasting blood sugar, systolic, and diastolic blood pressure (BP). After complete description of the study to the seafarers, informed consents were filled out by all participants.

\section{MEASUREMENT}

Weight, height, and BP of the participants were measured by a trained physician of Health Unit of NITC. Participants removed their shoes and wore light clothing for anthropometric measurements. Weight was measured using an electronic scale (Seca, 707; range 0.1-150 kg), and height was measured using a tape meter stadio-meter according to standard protocols [12]. Waist circumference (WC) was measured at umbilicus level with $1 \mathrm{~mm}$ accuracy. Body mass index (BMI) was then calculated $\left(\mathrm{BMI}=\mathrm{W} / \mathrm{H}^{2}\right.$ in which ' $\mathrm{W}$ ' is weight in kilograms and ' $\mathrm{H}$ ' is height in meters). Systolic and diastolic BP were measured twice and averaged, while participants were in a seated position after 15 min rest using a standard mercury sphygmomanometer calibrated by the Iranian Institute of Standards and Industrial Research.

Fasting blood sugar, serum levels of triglyceride (TG), total cholesterol (TC), and high-density lipoprotein cholesterol (HDL-C) were tested using the relevant kits obtained from the Pars Azmoon Company, Iran, by an automatic analytical machine after 12-14 $\mathrm{h}$ fasting (BT3000, Italy). Serum levels of low-density lipoprotein cholesterol (LDL-C) were determined according to the Friedewald formula: LDL-C = TC - (HDL-C + VLDL-C), where VLDL-C is very low-density lipoprotein cholesterol [13]. Atherogenic index (Al) was calculated by the following formula: (TC - HDL-C) / HDL-C [14]; LDL-C / HDL-C ratio was calculated as the ratio of plasma LDL-C to HDL-C levels.

Metabolic syndrome was diagnosed according to the recommendations of National Committee of Obesity [2]. Seafarers who had at least three of the following criteria were classified as patients with MetS: $W C>95 \mathrm{~cm}, \mathrm{TG}$ $>150 \mathrm{mg} / \mathrm{dL}, \mathrm{HDL}-\mathrm{C}<40 \mathrm{mg} / \mathrm{dL}$, systolic BP > $130 \mathrm{~mm} \mathrm{Hg}$ and/ or diastolic BP $>85 \mathrm{~mm} \mathrm{Hg}$, and fasting blood glucose $>100 \mathrm{mg} / \mathrm{dL}$.

Three main parameters of high TC, high LDL-C, and general obesity were included in this study as other cardio metabolic risk factors. High TC and LDL were defined as TC $\geq 200 \mathrm{mg} / \mathrm{dL}$ and $\mathrm{LDL} \geq 130 \mathrm{mg} / \mathrm{dL}$, respectively. General obesity was considered $B M I \geq 30 \mathrm{~kg} / \mathrm{m}^{2}$. Abdominal obesity was defined as waist circumference $>95 \mathrm{~cm}$ for men and excessive weight was defined as $\mathrm{BMI}>25 \mathrm{~kg} / \mathrm{m}^{2}$.

\section{STATISTICAL ANALYSIS}

The data were analysed by the Statistical Package for the Social Sciences software, version 16 (SPSS Inc., Chicago, IL, USA). Categorical variables were reported in numbers (n) and per cent (\%). Continuous variables were presented in mean and standard deviation (SD). The t-test was used to compare continuous variables and $\chi 2$ to compare categorical variables. Association of independent variables and MetS components was assessed using linear regression model. The significant level was set at $p<0.05$.

\section{RESULTS}

The mean age of the participants was $36.0 \pm 10.3$ years, and $163(69.7 \%)$ and 92 (39.3\%) of the participants had academic degree, and their job history were more than 10 years. Respectively, $70.1 \%$, and $27.8 \%$ of seafarers had shift work, and were smokers. Participants with MetS were older than those without MetS $(44.1 \pm 10.9$ years vs. $34.6 \pm 9.5$ years $)$. The mean weight $(87.5 \pm 10.6 \mathrm{~kg})$ and BMI $\left(27.9 \pm 2.7 \mathrm{~kg} / \mathrm{m}^{2}\right)$ were significantly higher among people with MetS compared with those without MetS $\left(78.1 \pm 11.2 \mathrm{~kg}\right.$ and $24.8 \pm 3.1 \mathrm{~kg} / \mathrm{m}^{2}$, respectively). A significant difference was observed in WC between seafarers with MetS and without MetS (<0.001). Systolic and diastolic BP mean values in MetS group were $128.8 \pm$ $\pm 16.8 \mathrm{~mm} \mathrm{Hg}$ and $81.9 \pm 8.0 \mathrm{~mm} \mathrm{Hg}$, respectively, and higher than in participants without MetS $(<0.05)$. In the seafarers with MetS, the TG mean, TC, and HDL-C were higher than in seafarers without MetS. Also, the LDL/HDL mean, TC/HDL, and VLDL in MetS group were higher than in seafarers without MetS (Table 1).

Totally, $8.6 \%$ and $38.5 \%$ of the participants were obese and had abdominal obesity. The rates of high systolic and 
Table 1. Description of some quantitative characteristics of metabolic syndrome and non-metabolic syndrome groups

\begin{tabular}{|c|c|c|c|c|}
\hline & \multicolumn{2}{|c|}{ Metabolic syndrome } & \multirow[t]{2}{*}{ Total $(n=234)$} & \multirow[t]{2}{*}{$\mathbf{P}$} \\
\hline & Yes $(n=35)$ & No $(n=199)$ & & \\
\hline Age [years] & $44.1 \pm 10.9$ & $34.6 \pm 9.5$ & $36.0 \pm 10.3$ & $<0.001$ \\
\hline Height [cm] & $176.9 \pm 8.3$ & $177.2 \pm 6.2$ & $177.2 \pm 6.6$ & NS \\
\hline Weight [kg] & $87.5 \pm 10.6$ & $78.1 \pm 11.2$ & $79.5 \pm 11.6$ & $<0.001$ \\
\hline Body mass index $\left[\mathrm{kg} / \mathrm{m}^{2}\right]$ & $27.9 \pm 2.7$ & $24.8 \pm 3.1$ & $25.3 \pm 3.2$ & $<0.001$ \\
\hline Waist circumference [cm] & $97.6 \pm 9.1$ & $89.8 \pm 10.3$ & $90.9 \pm 10.5$ & $<0.001$ \\
\hline Systolic BP [mm Hg] & $128.8 \pm 16.8$ & $121.6 \pm 11.6$ & $122.6 \pm 12.7$ & $<0.05$ \\
\hline Diastolic BP [mm Hg] & $81.9 \pm 8.0$ & $77.4 \pm 8.4$ & $78.1 \pm 8.5$ & $<0.05$ \\
\hline Fasting blood glucose [mg/dL] & $109.0 \pm 25.5$ & $92.9 \pm 16.2$ & $95.3 \pm 18.7$ & NS \\
\hline Triglyceride [mg/dL] & $226.3 \pm 72.5$ & $108.8 \pm 55.1$ & $126.4 \pm 71.5$ & $<0.001$ \\
\hline Cholesterol [mg/dL] & $198.8 \pm 39.7$ & $177.3 \pm 41.2$ & $180.5 \pm 41.6$ & $<0.001$ \\
\hline $\mathrm{HDL}-\mathrm{C}[\mathrm{mg} / \mathrm{dL}]$ & $41.8 \pm 8.8$ & $46.8 \pm 10.1$ & $46.0 \pm 10.0$ & $<0.05$ \\
\hline LDL-C [mg/dL] & $110.7 \pm 36.8$ & $108.9 \pm 32.1$ & $109.2 \pm 32.7$ & NS \\
\hline LDL/HDL & $2.6 \pm 0.7$ & $2.3 \pm 0.6$ & $2.4 \pm 0.6$ & $<0.05$ \\
\hline Total cholesterol/HDL & $4.8 \pm 0.9$ & $3.8 \pm 0.8$ & $3.9 \pm 0.8$ & $<0.001$ \\
\hline VLDL & $45.3 \pm 15.6$ & $21.7 \pm 11.0$ & $25.2 \pm 14.4$ & $<0.001$ \\
\hline
\end{tabular}

*T-test; BP - blood pressure; HDL-C - high-density lipoprotein cholesterol; LDL-C - low-density lipoprotein cholesterol; VLDL-C - very low-density lipoprotein cholesterol

diastolic BP, and hypertension were $34.3 \%, 31.4 \%$, and $60.0 \%$ in seafarers with MetS, respectively. The per cent of diabetes, high TG, TC, and low HDL were $23.1 \%, 25.2 \%$, $28.2 \%$, and $26.5 \%$, respectively (Table 2). The prevalence of MetS was $14.9 \%$ among Iranian seafarers (Fig. 1).

About $10 \%$ of seafarers had three MetS components. Totally, $4.6 \%$ of the participants had 4 and 5 MetS components (Fig. 2).

Multivariate logistic regressions are presented in Table 3. In multivariate analysis, BMI is associated with increase in abdominal obesity (OR: $1.40,95 \% \mathrm{Cl}$ : 1.25-1.57), high TC (OR: 1.19, 95\% Cl: 1.02-1.23), hypertension (OR: 1.14, 95\% Cl: 1.01-1.27), and MetS (OR: 1.32, 95\% Cl: 1.15-1.51). Older age was associated with increase in obesity, high TG, hypertension, and MetS, i.e. the odds ratio per year of age was 1.07 for obesity, 1.05 for high TG, 1.05 for hypertension, and 1.07 for MetS.

The prevalence of cardio-metabolic risk factors and MetS were shown in Figure 1. The per cent of subjects with excessive weight and abdominal obesity were 51.1, and $38.5 \%$, respectively, which were higher than other risk factors.

\section{DISCUSSION}

The findings showed that the prevalence of MetS was about $15 \%$, and a large proportion of seafarers had abdominal obesity. A study was performed among Danish seafarers, showing that the prevalence of MetS was 25.9\% and this prevalence increased with age [5]; a similar status was seen in the present study, i.e. the risk of MetS increased by increase of $1 \mathrm{SD}$ in age. High prevalence of the MetS has been reported from Sub-Saharan Africa and Middle East countries; South Africa, Morocco, Oman, Turkey, and Iran showed prevalence of 33.5, 16.3, 21, 33.4, and 33.7\%, respectively [15]. The prevalence of the MetS is highly age-dependent. This pattern is clear in Iran where the prevalence is less than $10 \%$ for both men and women in the 20-29 year age group, rising to $38 \%$ and $67 \%$, respectively, in the $60-69$ year agegroup [16]. The observed difference between prevalence of MetS between our study and general population of Iran can be attributed to difference in age range of studied subjects. On the other hand, perhaps using various criteria for MetS definition or higher sensitivity to health in this group due to annually health examination tests could cause differences in its prevalence in different studies.

Previous studies suggest that smoking $[9,17]$ and job duration $[17,18]$ are risk factors for chronic heart diseases (CHD) among seafarers. A study performed among seafarers of abroad German-flagged ships showed that seafarers having smoking habit were at a higher CHD risk [9]. The odds ratio of cardiovascular disease for seafarers who smoked cigarettes was 2.95 in INTERHEART study [19]. Other studies also confirmed that smoking cigarettes was prevalent among seafarers $[17,20]$ because of work related stress and lack of leisure time facilities [17]. Similar results were observed in our study, and cigarette consumption was com- 
Table 2. The qualitative characteristics of the participants according to metabolic syndrome

\begin{tabular}{|c|c|c|c|c|}
\hline & \multicolumn{2}{|c|}{ Metabolic syndrome } & \multirow[t]{2}{*}{ Total $(n=234)$} & \multirow[t]{2}{*}{$\mathbf{P}$} \\
\hline & Yes $(n=35)$ & No $(n=199)$ & & \\
\hline Educational level: & & & & $<0.05^{\star}$ \\
\hline Diploma & $17(48.6 \%)$ & $54(27.1 \%)$ & $71(30.3 \%)$ & \\
\hline Academic & $18(51.4 \%)$ & 145 (72.9\%) & $163(69.7 \%)$ & \\
\hline Job history: & & & & $<0.001$ \\
\hline$\leq 10$ year & $9(25.7 \%)$ & $133(66.8 \%)$ & $142(60.7 \%)$ & \\
\hline$>10$ year & $26(74.3 \%)$ & $66(33.2 \%)$ & $92(39.3 \%)$ & \\
\hline Shift work: & & & & NS \\
\hline No & $15(42.9 \%)$ & $55(27.6 \%)$ & 70 (29.9\%) & \\
\hline Yes & $20(57.1 \%)$ & $144(72.4 \%)$ & $164(70.1 \%)$ & \\
\hline BMI category: & & & & $<0.001$ \\
\hline Normal & 7 (20.0\%) & 107 (54.0\%) & 114 (48.9\%) & \\
\hline Overweight & 20 (57.1\%) & 79 (39.9\%) & 99 (42.5\%) & \\
\hline Obese & $8(22.9 \%)$ & $12(6.1 \%)$ & $20(8.6 \%)$ & \\
\hline Smoking status: & & & & NS \\
\hline No & 22 (62.9\%) & 147 (73.9\%) & $169(72.2 \%)$ & \\
\hline Yes & $13(37.1 \%)$ & $52(26.1 \%)$ & $65(27.8 \%)$ & \\
\hline Abdominal obesity & $26(74.3 \%)$ & 64 (32.2\%) & 90 (38.5\%) & $<0.001^{* *}$ \\
\hline High systolic BP & $12(34.3 \%)$ & $16(8.0 \%)$ & $28(12.0 \%)$ & $<0.001$ \\
\hline High diastolic BP & 11 (31.4\%) & $15(7.5 \%)$ & 26 (11.1\%) & $<0.001$ \\
\hline Hypertension & $21(60.0 \%)$ & 24 (12.1\%) & 45 (19.2\%) & $<0.001$ \\
\hline Diabetes & 22 (62.9\%) & 32 (16.1\%) & $54(23.1 \%)$ & $<0.001$ \\
\hline High TG & 32 (91.4\%) & 27 (13.6\%) & $59(25.2 \%)$ & $<0.001$ \\
\hline High TC & $15(42.9 \%)$ & $51(25.6 \%)$ & $66(28.2 \%)$ & $<0.05$ \\
\hline Low HDL & $16(45.7 \%)$ & $46(23.1 \%)$ & 62 (26.5\%) & $<0.01$ \\
\hline High LDL & 10 (28.6\%) & 52 (26.1\%) & 62 (26.5\%) & NS \\
\hline
\end{tabular}

${ }^{*} \chi^{2}$, ${ }^{*}$ T-test; BMI - body mass index; BP - blood pressure; HDL - high-density lipoprotein cholesterol; LDL-C - low-density lipoprotein cholesterol; TC - total cholesterol; $\mathrm{TG}$ - triglyceride

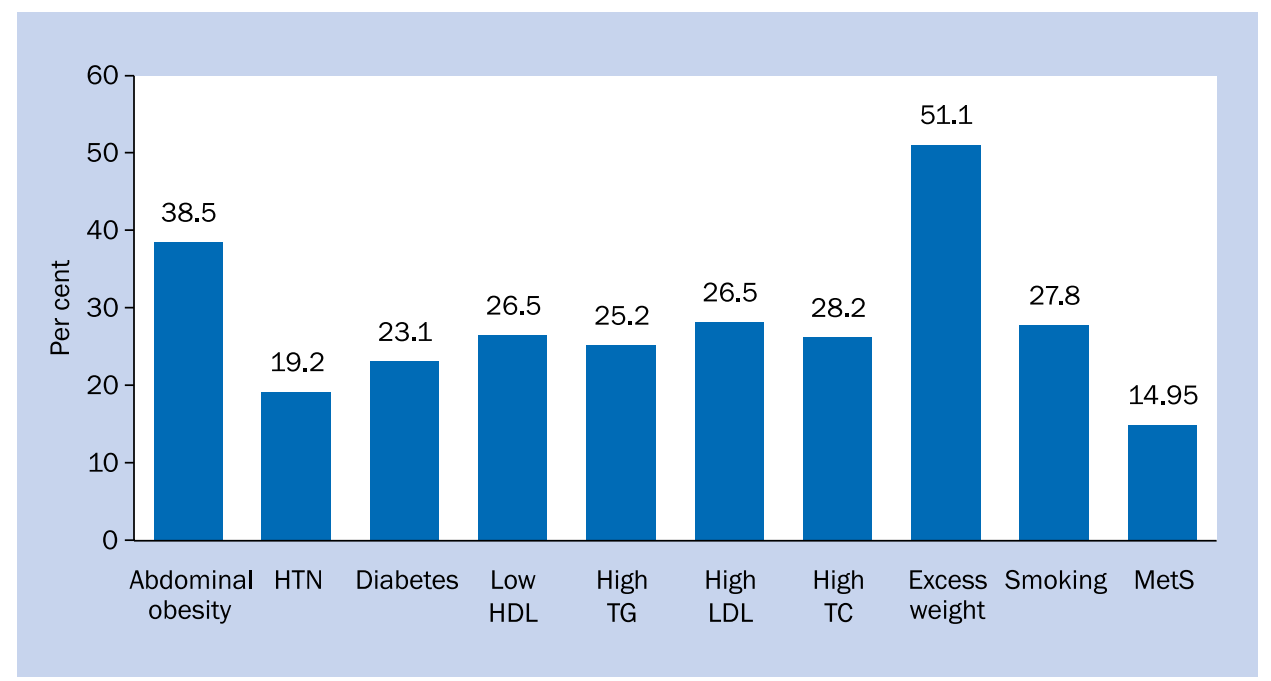

Figure 1. Prevalence of cardio-metabolic risk factors and metabolic syndrome (MetS); HDL - high-density lipoprotein cholesterol; HTN - hypertension; LDL - low-density lipoprotein cholesterol; TC - total cholesterol; TG - triglyceride 


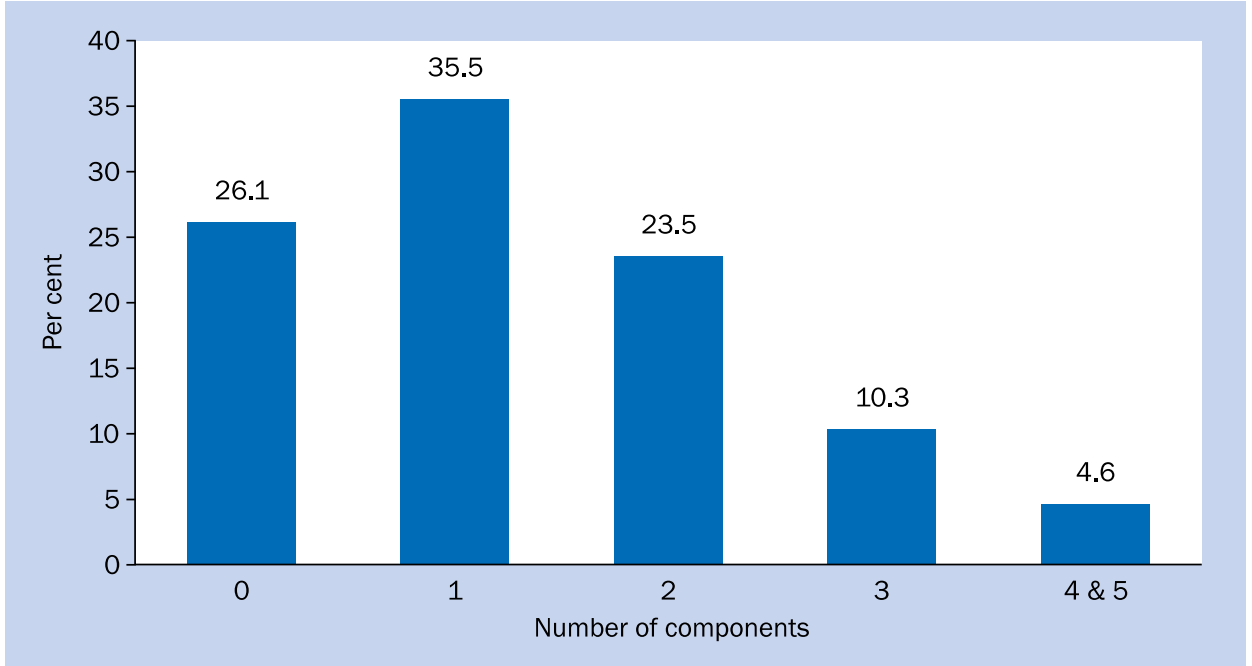

Figure 2. Prevalence of the number of metabolic syndrome components in seafarers

Table 3. Odds ratio (95\% confidence interval) for association between independent variables with metabolic syndrome components in multivariable model

\begin{tabular}{|c|c|c|c|c|c|}
\hline & Age (year) & $\begin{array}{l}\text { Education (Acade- } \\
\mathrm{mic} / \text { diploma) }\end{array}$ & Shift type (Yes) & Smoking (Yes/No) & BMI $\left[\mathrm{kg} / \mathrm{m}^{2}\right]$ \\
\hline Abdominal obesity & $1.03(0.995-1.06)$ & $0.45(0.125-1.644)$ & $2.62(0.733-9.37)$ & $1.04(0.521-2.08)$ & $1.40(1.25-1.57)^{\star}$ \\
\hline Obesity & $1.07(1.02-1.13) \dagger$ & $2.87(0.310-26.7)$ & $1.015(0.123-8.40)$ & $0.76(0.258-2.28)$ & - \\
\hline High triglyceride & $1.05(1.02-1.09) \ddagger$ & $0.71(0.196-2.59)$ & $1.24(0.352-4.41)$ & $1.03(0.508-2.08)$ & $1.10(0.999-1.22$ \\
\hline Low HDL & $1.03(0.996-1.06)$ & $1.14(0.321-4.05)$ & $1.42(0.412-4.88)$ & $0.93(0.483-1.83)$ & $1.01(0.920-1.11)$ \\
\hline High LDL & $0.992(0.959-1.03)$ & $0.86(0.258-2.89)$ & $0.70(0.217-2.27)$ & $0.77(0.390-1.53)$ & $1.05(0.958-1.16$ \\
\hline High cholesterol & $0.98(0.957-1.02)$ & $0.92(0.280-3.03)$ & $0.705(0.221-2.24)$ & $0.71(0.359-1.41)$ & $1.19(1.02-1.23) \ddagger$ \\
\hline High systole & $1.08(1.03-1.12) \ddagger$ & $0.44(0.08-2.36)$ & $1.84(0.357-9.48)$ & $0.74(0.282-1.95)$ & $1.10(0.962-1.26)$ \\
\hline High diastole & $1.01(0.963-1.05)$ & $0.39(0.08-1.93)$ & $0.84(0.182-3.96)$ & $1.09(0.425-2.80)$ & $1.16(1.01-1.34) \ddagger$ \\
\hline Hypertension & $1.05(1.01-1.09) \dagger$ & $0.47(0.118-1.90)$ & $1.11(0.283-4.33)$ & $0.60(0.262-1.39)$ & $1.14(1.01-1.27) \ddagger$ \\
\hline Diabetes & $1.03(0.991-1.06)$ & $1.11(0.307-3.98)$ & $0.65(0.190-2.23)$ & $0.90(0.448-1.84)$ & $1.07(0.965-1.18$ \\
\hline Metabolic syndrome & $1.07(1.02-1.11) \dagger$ & $0.62(0.127-3.11)$ & $1.62(0.340-7.74)$ & $1.51(0.626-3.62)$ & $1.32(1.15-1.51)^{\star}$ \\
\hline
\end{tabular}

mon among Iranian seafarers. Job duration at sea is one of $\mathrm{CHD}$ risk factors among seamen, and a previous investigation showed that seafarers who had longer job history at sea had about threefold increased risk of having coronary risk factors [17]. In our study, the prevalence of MetS was more common among seafarers with more than 10-year job history than seamen with less than 10-year job history. The results of a study among Polish seafarers presented that the mean experience of job duration at sea was 20.6 years, and because of the lack of a qualified officer, the retirement age increased and it was expected that the risk of $\mathrm{CHD}$ would rise during the coming years [21]. In other studies, the occurrence of MetS was associated with shift work [22, 23]. Violanti et al. (2009) [22] revealed that midnight shift work was significantly associated with MetS components, and likely the main contributors to the MetS. In the present research study, shift work was not associated with the risk of MetS among Iranian seafarers. Also, in the study of Canuto et al. [10], it was observed that shift work was not related to MetS. In the causal pathway that connects shift work to MetS, probably sleep duration is a confounder [24] which was not included in the current study and analyses. Previous studies have indicated that MetS and associated risk factors are more prevalent among seafarers compared with general population $[25,26]$. Seafarers work in periods of months on Tanker followed by a few-month vacation which may contribute to different life-styles compared with other individuals [27].

In the current study, cardio-metabolic risk factors: diabetes, high TG, high TC, low HDL-C, high LDL-C, and abdominal 
obesity preponderated with a frequency between $23 \%$ and $39 \%$. High cardio-metabolic risk is confirmed in previous studies [9, 17]. Oldenburg et al. [17] showed that the rate of high triglyceridaemia (> $150 \mathrm{mg} / \mathrm{dL}$ ) and high LDL-C among marines was about $41.6 \%$ and $18 \%$, respectively. In a study in Germany on 35\% of seafarers, there were at least 3 coronary heart disease risk factors, and the main risk factors were high triglycerides, hypertension, and ageing [9]. Other published data suggested that overweight was one of the main risk factors among seafarers [28], which is consistent with the current result that indicated abdominal obesity as a principal cardio-metabolic risk factor among Iranian seafarers (38.5\%). Seafarers live and work differently from most of the other people and their conditions lead them to suffer from some special diseases [29]. Documentaries show that the majority of seafarers' death is related to cardiovascular disease [30]. During stays on Tanker over several months, seafarers have restricted leisure time facilities which can contribute to physical inactivity and consequently to obesity. Also, it is described that job duration, work-related stress, and reduced duration of sleep were associated with cardiovascular risk factors [30]. Moreover, as cooks employed in Tankers are not adequately trained, unhealthy eating pattern among seafarers can be accounted as a major risk factor for cardiovascular disease [29].

\section{STUDY LIMITATIONS AND STRENGTHS}

The limitation of the study is its cross-sectional design. The main strength of the study is the fact that this is, to the best of our knowledge, the first study that assessed the prevalence of cardio-metabolic and associated risk factors among Iranian seafarers working on tankers.

\section{CONCLUSIONS}

Our findings showed that the current prevalence of MetS among Iranian male seafarers working on tankers can affect negatively their health and career at sea. In this regard, more standardised identification of seafarers with elevated cardiac risk factors during the fitness test, with emphasis on obviously more prevalent ones, for controlling mentioned health problems should become a priority in Iranian maritime industry. Future preventive interventions for health promotion of seafarers, especially those working on tankers, are recommended.

\section{AUTHORS' CONTRIBUTIONS}

Dr. Olaf $C$ Jensen and Dr. Farzad Shidfar conceived of the study and revised the manuscript. Fereshteh Baygi participated in study design and wrote a draft of the manuscript. Dr. Mostfa Qorbani conceived of the study and carried out the statistical analysis. Seyed Ali Salehi, Dr. Fatemeh Mohammadi, Dr. Aliasghar Farshad participated in its design and implementation. Hamid Asayesh edited the manuscript. All authors read and approved the final manuscript.

\section{ACKNOWLEDGEMENTS}

The source of data used was derived from the $\mathrm{PhD}$ thesis of Ms. Fereshteh Baygi, a student of the Occupation Health Research Centre of Iran University of Medical Sciences. The authors would like to thank the manager and participants of NITC for their important contribution.

\section{ETHICAL CONSIDERATIONS}

This study was proposed and approved by the Ethics-in-Research Commission of Iran University of Medical Sciences. Also, informed consent was obtained from all individual participants included in the study.

\section{FUNDING}

This study was funded by Iran University of Medical Sciences (grant No. 25800).

\section{CONFLICT OF INTEREST}

The authors declare that they have no competing interests.

\section{REFERENCES}

1. Eckel RH, Grundy SM, Zimmet PZ. The metabolic syndrome. Lancet 2005; 365: 1415-1428.

2. Fereidoun Azizi M, Farzad Hadaegh M, Davood Khalili M et al. Appropriate definition of metabolic syndrome among Iranian adults: Report of the Iranian National Commit-tee of Obesity. Arch Iran Med, 2010; 13: 426.

3. Nichols M, Townsend N, Scarborough P, Rayner M. European cardiovascular disease statistics 2012.

4. Mohan V, Deepa M. The metabolic syndrome in developing countries. Diabetes Voice 2006; 51: Special Issue.

5. Pedersen SFM, Jepsen JR. The metabolic syndrome among Danish seafarers. Int Marit Health 2013; 64: 183-190.

6. Hartenbaum N, Zee P. Shift work and sleep optimizing health, safety, and performance. J Occup Environmental Med 2011; 53.

7. Almadi T, Cathers I, Chow CM. Associations among work related stress, cortisol, inflammation, and metabolic syndrome. Psychophysiology 2013; 50: 821-830.

8. Kaltsas G, Vgontzas A, Chrousos G. Fatigue, endocrinopathies, and metabolic disorders. PM\&R 2010; 2: 393-398.

9. Oldenburg M, Jensen H-J, Latza U, Baur X. Coronary risks among seafarers aboard German-flagged ships. Int Arch Occupat Environmental Health 2008; 81: 735-741.

10. Canuto R, Pattussi MP, Macagnan JBA, Henn RL, Olinto MTA. Metabolic syndrome in fixed-shift workers. Revista de Saude Publica 2015; 49: 1-8.

11. Roberts SE. Mortality from disease among seafarers in British merchant shipping (1976-1995). Int Marit Health 2001; 53 (1-4): 43-58.

12. NHLBI Obesity Education Initiative. The Practical Guide Identification, Evaluation, and Treatment of Overweight and Obesity in Adults $\mathrm{Na}$ tional Institutes of Health, National Heart, Lung, and Blood Institute, 
NHLBI Obesity Education Initiative, North American Association for the Study of Obesity, 2000.

13. Friedewald WT, Levy RI, Fredrickson DS. Estimation of the concentration of low-density lipoprotein cholesterol in plasma, without use of the preparative ultracentrifuge. Clin Chem 1972; 18: 499-502.

14. Harnafi H, Caid HS, el Houda Bouanani N, Aziz M, Amrani S. Hypolipemic activity of polyphenol-rich extracts from Ocimum basilicum in Triton WR-1339-induced hyperlipidemic mice. Food Chem 2008; 108: 205-212.

15. Misra A, Khurana L. Obesity and the metabolic syndrome in developing countries. J Clin Endocrinol Metab 2008; 93: S9-S30.

16. Azizi F, Salehi P, Etemadi A, Zahedi-AsI S. Prevalence of metabolic syndrome in an urban population: Tehran Lipid and Glucose Study. Diabetes Res Clin Pract 2003; 61: 29-37.

17. Oldenburg M, Jensen $\mathrm{H}-\mathrm{J}$, Latza U, Baur X. The risk of coronary heart disease of seafarers on vessels sailing under a German flag. Int Marit Health 2010; 62: 123-128.

18. Assmann G, Cullen P, Schulte H. Simple scoring scheme for calculating the risk of acute coronary events based on the 10-year follow-up of the prospective cardiovascular Münster (PROCAM) study. Circulation 2002; 105: 310-315.

19. Teo KK, Ounpuu S, Hawken $S$ et al. Tobacco use and risk of myocardial infarction in 52 countries in the INTERHEART study: a case-control study. Lancet 2006; 368: 647-658.

20. Kirkutis A, Norkiene S, Griciene P, Gricius J, Yang S, Gintautas J eds. Prevalence of hypertension in Lithuanian mariners. Proc West Pharmacol Soc 2004: Citeseer.
21. Jaremin B, Kotulak E. Myocardial infarction (MI) at the work-site among Polish seafarers. The risk and the impact of occupational factors. Int Marit Health 2002; 54: 26-39.

22. Violanti JM, Burchfiel CM, Hartley TA et al. Atypical Work Hours and Metabolic Syndrome Among Police Officers. Arch Environment Occupat Health 2009; 64: 194-201.

23. Lin Y-C, Hsiao T-J, Chen P-C. Persistent Rotating Shift-Work Exposure Accelerates Development of Metabolic Syndrome among Middle-Aged Female Employees: A Five-Year Follow-Up. Chronobiol Int 2009; 26: $740-755$.

24. Canuto R, Garcez AS, Olinto MT. Metabolic syndrome and shift work: a systematic review. Sleep Med Rev 2013; 17: 425-431.

25. Hjarnoe L, Leppin A. A risky occupation? (Un) healthy lifestyle behaviors among Danish seafarers. Health Promotion Int. 2013:dat024.

26. Pancić M, Rička-Žauhar Z, Blažević M eds. Analysis of risk factors and assessment of exposure to coronary diseases in seamen. Eigth international symposium on maritime health, Rijeka, Croatia; 2005.

27. Hoeyer JL, Hansen HL. Obesity among Danish seafarers. Int Marit Health 2005; 56: 48-55.

28. Pougnet R, Pougnet L, Loddé BL et al. Cardiovascular risk factors in seamen and fishermen: review of literature. Int Marit Health 2013; 64: 107-113.

29. Alderton T, Bloor M, Kahveci E et al. The Global Seafarer: Living and Working Conditions in a Globalized Industry. Geneva: Seafarers International, Research Centre, International Labour Office; 2004.

30. Oldenburg M. Risk of cardiovascular diseases in seafarers. Int Marit Health 2014; 65: 53-57. 